\title{
Methods of assessing functioning of organizational and economic mechanism during innovation process implementation
}

\author{
Maksim Blinkov ${ }^{1, *}$, and Oleg Blinkov ${ }^{1}$ \\ ${ }^{1}$ Mechanics and Machine Building Institute, Ural Federal University, Russia
}

\begin{abstract}
This paper proposes methods of assessing the efficiency of organizational and economic mechanism of an industrial enterprise when implementing innovation processes. These methods allow continuous monitoring at all stages of innovation process implementation, lead to reduction in costs of innovation activity and enable maximum use of the creative potential of enterprise personnel. The significance and attractiveness of this method is ensured by the fact that it can be applied by industrial companies in any market fields regardless of the lifecycle stage applicable to the studied goods, company and/or innovative process because the composition and the number of specific indicators can be adjusted by the work group both before the study and in the course of the company's innovative activities (at any stage of their implementation). The multi-sided approach proposed for assessing the efficiency of organizational and economic mechanism of the industrial enterprise when implementing innovation processes ensures full and accurate assessment of the impact of certain factors on the final result.
\end{abstract}

\section{Introduction}

In the literature on economics, assessment of functioning of any mechanisms, as a rule, is performed by using the indicators which compare the results of certain activities with input required for their performance, i.e. efficiency [1]. Thus, increased efficiency shall mean better results at reduced or equal input [2]. However, a number of scientific publications express the opinion that when giving assessment, both efficiency and effectiveness should be considered. Thus, for example, in the commonly known work of Mescon, Albert and Khedouri, effectiveness means the capability to "do the right thing", whereas efficiency means "doing the things right" [3]. In terms of assessment of efficiency in implementation of innovation processes, this approach is of special interest, in our opinion. Indeed, when producing a certain innovation (in the form of a new product, technology, management or organization method, etc.), which is a result of innovative process, it is extremely important not only to obtain the innovation with minimum costs but to make the innovation in demand, i.e., it must correspond to certain needs both of the company that initiated its implementation and the market in which the company operates.

\section{Methods of assessing the efficiency of organizational and economic mechanism}

In addition to the characteristics of innovation process implementation in terms of effectiveness and economic efficiency, the management efficiency should be assessed taking into account another important factor time [4], i.e., the period of time required to achieve the set goal. If the innovative activities performed are both in demand to the required extent, and economically efficient to the sufficient extent, but the overall process for obtaining these innovations is longer compared with the average duration of innovative processes at similar companies, it is obvious that the efficiency of functioning of organizational and economic mechanisms for implementation of innovation processes at this company or enterprise will be lower that at the companies which achieve similar results within a shorter timeframe [5].

Thus, assessment of functioning of organizational and economic mechanisms (OEM) in implementation of innovation processes shall be performed using the following three key criteria:

- Effectiveness, i.e., capability to produce innovations which contribute to the achievement of set goals as a result of innovation processes;

- Economic efficiency, i.e., capability to obtain necessary innovations at the allowed level of expenses;

- Time or capability to achieve the required results over a certain period of time.

We propose that the functioning of organizational and economic mechanism should be assessed in three stages:

\footnotetext{
Corresponding author: agamberg@mail.ru
} 
1. Assess the effectiveness of the innovation process implemented by the company;

2. Assess the practical application of methodological principles of organizational and economic mechanism for implementation of innovation processes;

3. Assess the effects of innovative activities on the basis of integrated indicators obtained at the first and second stages.I

Specific features of information

Additionally, it should be noted that indicators for assessment of OEM functioning were selected considering the following specific features of information:

Objectivity and controllability. Indicators with values comparable with the values for prior periods should be used. The number of cases where the indicators are redetermined over time should be minimized. The method for collection and processing of input data should provide for the possibility to check the accuracy of obtained data in the course of independent monitoring.

Adequacy of reflection of ongoing changes. The indicators shall form a reliable base for assessment of innovation effectiveness. The data must be sufficiently accurate for the purpose of its use and should be obtained on a regular basis (i.e., at strictly defined intervals) and in due time.

Economic efficiency. Capability to obtain necessary data without exceeding the economically feasible cost limits. The indicator should be based on the already available information.

Conformance to the set goal (relevance). Each individual indicator must be aimed at measurement of progress in resolution of a certain task.

Accuracy and unambiguity. The indicators should be selected considering the need to continuously accumulate data and ensure their comparability over certain time periods. The essence of the indicator must be clear to the members of the work group performing the calculations and to the department managers.

Aspects of effectiveness of the innovation process.

In our opinion, effectiveness of the innovation process should be assessed in three aspects: organizational and management, social and production [6].

1.Organizational and management effectiveness reflects the degree of optimization of production system hierarchical pattern, level of correlation between coordination and subordination ties in it, possibilities for implementation of organizational potential and achieving maximum output from management actions. The integrated indicator which determines the organizational effectiveness of the innovative process is represented by (OR), eqn.(1):

$$
O R=\sqrt[3]{T_{d e p} * T_{s m} * T_{m}}
$$

where Tdep - coefficient of profitable departments; Tsm - structuredness of management personnel; $\mathrm{Tm}$ - manageability of management personnel.

Coefficient of profitable departments, i.e., those directly involved in the product lifecycle and making considerable contribution to the economic result achieved by the company, eqn.(2):

$$
T_{\text {dep }}=K_{\text {department }} / D a
$$

where Kdepartment $\quad-$ number of profitable departments;

$\mathrm{Da}$ - actual number of departments.

Structuredness of management personnel, eqn.(3):

$$
T_{s m}=\sum(D r * H r) / \sum(D a * H a),
$$

where Dr - regulatory number of structural divisions;

$\mathrm{Hr}$ - regulatory headcount of management personnel;

Ha - actual headcount of management personnel.

Manageability of management personnel, eqn.(4):

$$
T_{m}=\frac{1}{Z} * \sum_{i} \frac{H_{a i}}{H_{r i}}
$$

where $\mathrm{i}=1, \ldots, \mathrm{Z}$ - number of management levels;

Hai and Hri - actual and regulatory number of employees assigned to one manager at the ith management level on the average.

2. Social effectiveness of the innovative process reflects the consumer and social significance for the society and certain individuals observed in the course of consumption of newly created or improved material products. The integrated value which determines the social effectiveness of the innovative process is represented by (SR), eqn.(5):

$$
S R=\sqrt[2]{C_{\text {quality }} * C_{\text {ecolog } y}},
$$

where Cquality - quality coefficient (determined based on department indicators);

Cecology - coefficient of environmental safety of production activity (determined based on department indicators) [7].

3. Production effectiveness reflects the increase in the level of production and technological activities of the company and quality of work performed by its employees. The integrated indicator which determines the production effectiveness of the innovative process is represented by (PR), eqn.(6):

$$
P R=\sqrt[4]{\left(T_{\text {aut }} * T_{\text {tech.prog }} * T_{\text {perform }}\right) /\left(T_{\text {defect }} * T_{\text {ritm }}\right)},
$$

where Taut - level of mechanization and automation of technological operation performance;

Ttech,prog - level of technological progress;

Tperform - performance;

Tdefect - loss due to defects to the volume of manufactured product;

Tritm - rhythmicity of production.

Level of mechanization and automation of technological operation performance, eqn.(7): 


$$
T_{\text {aut }}=Q_{\text {aut }} / Q,
$$

where Qaut - number of workers performing technological operations using machines and by supervision of automated machinery, people;

Q - number of workers participating in technological processes, people.

Level of technological progress, eqn.(8):

$$
T_{\text {tech.prog }}=Q_{\text {tech.prog }} / Q_{\text {tech }},
$$

where Qtech.prog - number of new and improved technological processes, pc.;

Q tech - total number of technological processes in accordance with technological documentation of the company, pc.

Performance, eqn.(9):

$$
T_{\text {perform }}=Q_{\text {volume_a }} / T,
$$

where Qvolume a - actual volume of issued goods, RUB;

$\mathrm{T}$ - time period, hours.

Losses due to defects to the volume of issued product, eqn.(10):

$$
T_{\text {defect }}=C_{\text {defect }} / Q_{\text {volume_a }},
$$

where $\mathrm{C}$ defect - losses from defects for the period, RUB.

Rhythmicity of production - the actual volume of goods issued in the first ten days period, RUB/hours.

The proposed system of integrated indicators reflects the effectiveness of innovation implementation and its application will contribute to the selection of further organizational modifications associated with this innovation and development of innovative management strategy at large.

After establishment of multi-aspect system of indicators for direct assessment of innovative process effectiveness, we propose that the graphic method should be used. Indices of integrated indicators are marked on the axes (study periods are the same - month, quarter, half year) to reflect the organizational and management, social and production effectiveness of the innovative process; further, the center of gravity of the triangle is identified to reflect the integrated result of studied innovative process and demonstrate graphically which indicators reacted in the greatest degree. Then, assessment of innovative process effectiveness focuses on tracking the dynamics of movement of this active point and analysis of its new position. Thus, the developed methods for assessment of innovation implementation effectiveness enable establishing the parameters for innovation modification and contribute to selection of further organizational modifications associated both with this innovation and with development of innovative management strategy at large; the methods can be applied both in the course of innovation implementation at any stage as the basis control element and for assessment of the final effectiveness of the innovative process.

Therefore, the following integrated indicators are proposed for use in assessment (see the Figure 1) [8].

\section{The practical application of methodological principles of organizational and economic mechanism}

Further, let us assess in more detail the practical application of methodological principles of organizational and economic mechanism of innovation process implementation at companies. The indicators reflecting the application of methodological principles of organizational and economic mechanism in the business practice in the course of implementation of innovations with various degree of complexity must conform to the requirements which we make to ensure the accuracy of assessment of modifications in conditions institutionalizing the innovative process implemented at the company and stimulating the development of the innovative activities in the company at large.

Namely:

1.Express the essence of organizational and economic mechanism for implementation of the innovative process and give qualitative and quantitative assessment of its functioning;

2. Have complex nature as required to obtain multiaspect characteristics of conditions impacting the institutionalizing of innovations at companies;

3. Ensure accuracy, completeness and timely manner of information obtaining to ensure flexible and adaptive management of innovative activities at large.

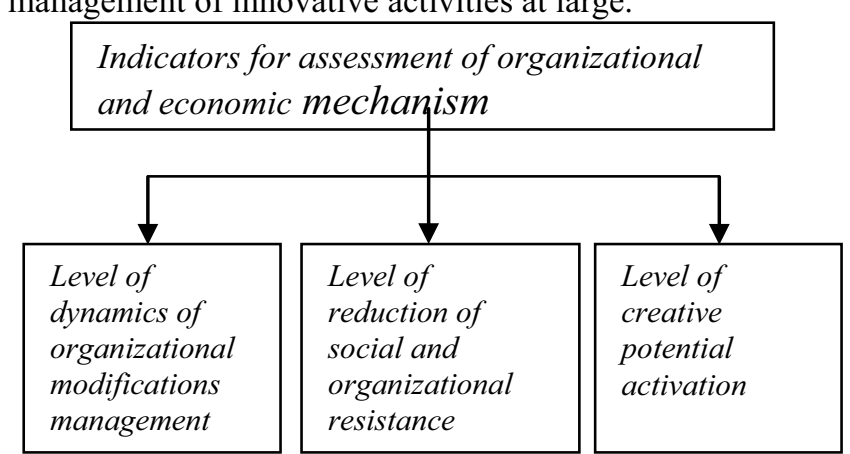

Fig. 1. Integrated Indicators of OEM for Innovative Process Implementation.

1. Take into account the possibility to change the conditions and tasks associated with development of the innovative activities at the company.

Thus, the overall assessment of functioning of organizational and economic mechanism will be performed as follows, eqn.(11):

$$
Y=a_{1} * Y_{D}+a_{2} * Y_{B}+a_{3} * Y_{A},
$$

where $\mathrm{YD}, \mathrm{YB}, \mathrm{YA}$ - level of dynamics in management of organizational modifications, level of reduction of social and organizational resistance, level of creative potential activation respectively; 
a1, a2, a3 - weigh (significance) coefficients of corresponding studied integrated indicators (to be determined by persons responsible for development of innovative activities or experts in the field of innovative solutions).

Additionally, assessment of each integrated indicator shall be performed in accordance with the common methodological basis, eqn.(12).

$$
Y=\sum b_{i} * \frac{T_{i_{-} a c t}}{T_{i_{-} \text {base }}},
$$

where Ti act, Ti base - ith indicator $(i=1,2,3, \ldots . n)$; $\mathrm{n}$ - number of indicators taken into account;

bi - weigh (significance) coefficient of ith indicator.

The level of dynamics in management of organizational modifications shall be determined as follows, eqn.(13):

$$
\begin{aligned}
& Y_{D}=b_{1} \frac{T_{\text {durat_a }} a}{T_{\text {durat_b }}}+b_{2} \frac{T_{\text {qualif_a }} a}{T_{\text {qualif_b }} b}+b_{3} \frac{T_{\text {closed_a }} a}{T_{\text {closed_b }} b}+b_{4} \frac{T_{\text {com_a }} a}{T_{\text {com_ } b}} \\
& +b_{5} \frac{T_{\text {progress_a }}}{T_{\text {progress_b }}},
\end{aligned}
$$

where Tdurat - time for experiment and time for implementation (the ratio tends to minimum);

Tqualif - number of cases where the employee's qualification corresponds to the work performed by the employee (the ratio tends to $100.0 \%$ );

Tclosed - number of vacancies closed as required for implementation of innovative process (the ratio tends to $100.0 \%$;

Tcom - the indicator in inter-structural communications (the ratio tends to $100.0 \%$ );

Tprogress - number of new technologies and methods of organization and management (the ratio tends to maximum).

The indicator of inter-structural communications shall be calculated as follows, eqn.(14):

$$
T_{\text {com }}=K_{\text {com_dep }} / K_{d e p}
$$

where Kcom dep - number of departments that exchange data in regulated and automated manner;

Kdep - total number of departments in the company.

The level of reduction of social and organizational resistance shall be determined as follows, eqn.(15):

$$
\begin{gathered}
Y_{B}=b_{1} \frac{T_{\text {debt_a }}}{T_{\text {debt_plan }}}+b_{2} \frac{T_{\text {inf_a }}}{T_{\text {inf_base }}}+b_{3} \frac{T_{\text {inf } o_{-} a} a}{T_{\text {inf } o_{-} b a s e}}+b_{4} \frac{T_{\text {decent_a }} a}{T_{\text {decent_ } b}} \\
+b_{5} \frac{T_{\text {perf_a }}}{T_{\text {perf_base }}}+b_{6} \frac{T_{\text {soc_a } a}}{T_{\text {soc_ } b}},
\end{gathered}
$$

where Tdebt - level of current debt owed to the employees in the form of salary (the ratio tends to 1);

Tinf - level of communication automation (the ratio tends to maximum);
Tinfo -indicator reflecting the sources and quality of information available for the employees engaged in the innovative process, falls within the interval $(0 ; 1)$, tends to 1 ;

Tdecent - indicator reflecting the engagement of personnel into the innovative process (the ratio tends to $100.0 \%$ );

Tperf - performance of the employees engaged into implementation of the innovative process, reflects the quality of work performed, falls within the interval $(0 ; 1)$, tends to 1 ;

Tsoc -indicator reflecting social tension (the ratio tends to the minimum).

The level of current debt owed to the employees in the form of salary, eqn.(16):

$$
T_{\text {debt }}=\left(A P S_{\text {accr }}-A P S_{\text {paid }}\right) / A P S_{\text {accr }},
$$

where APSaccr - employees' salary accrued for payment (minus income tax and contributions to nonbudgetary funds out of salary), RUB.

APSpaid - actually paid salary, RUB.

Level of communication automation, eqn.(17):

$$
T_{\text {inf }}=\left(M_{a} * K_{\text {inf_a } a}\right) /\left(M_{r} * K_{\text {inf_r } r}\right),
$$

where $\mathrm{Ma}, \mathrm{Mr}$ - actual and regulatory number of PCs used for making management resolutions in the course of innovative process implementation, pc.;

Kinf a - number of information technologies used for making management resolutions in the course of innovative process implementation, pc.;

Kinf $r$ - number of information technologies required for making management resolutions in the course of innovative process implementation, $\mathrm{pc}$.

Indicator of personnel involvement into the innovative process, eqn.(18):

$$
T_{\text {decent }}=C_{a} / C_{r}
$$

where $\mathrm{Ca}, \mathrm{Cr}$ - actual and regulated number of employees engaged into the innovative process, people.

Indicator of social tension, eqn.(19):

$$
T_{\text {soc }}=Q_{\text {conf }} / Q
$$

where Qconf - number of conflicts under review in the company departments and at administrative bodies, pc.;

$\mathrm{Q}$ - total number of employees, people.

Level of creative potential activation shall be determined as follows, eqn.(20):

$$
Y_{A}=b_{1} \frac{T_{\text {patent_a }} a}{T_{\text {patent_plan }}}+b_{2} \frac{T_{\text {creat_a }} a}{T_{\text {creat_base }}}+b_{3} \frac{T_{\text {prof_a }} a}{T_{\text {prof_base }}}+b_{4} \frac{T_{\text {turnover_a }},}{T_{\text {turnover_base }}},
$$

where Tpatent - number of registered rights to intellectual property, pc. (the ratio tends to maximum);

Tcreat - indicator of personnel's creative activity, to be determined based on the number of innovative 
proposals from employees involved into the innovative process, pc. (the ratio tends to maximum);

Tprof - indicator reflecting the level of professional training and qualification of employees, to be determined on the basis of attestation, falls within the range $(0 ; 1)$, tends to 1 ;

Tturnover - turnover of personnel (the ratio tends to minimum).

Indicator of personnel turnover, eqn.(21):

$$
T_{\text {turnover }}=Q_{\text {dismiss }} / Q
$$

where Qdismiss - number of employees who left voluntarily or were dismissed for violation of workplace discipline, people;

$\mathrm{Q}$ - total number of employees, people.

To assess the effects of innovative activities in the aspect of implemented innovative process, first of all, we need to identify the effects which reflect the comparison of results of innovative process implementation management with the costs associated with this management. The majority of Russian and foreign authors refer to the list specified in Table 1 [9]:

Table 3. Comparison of the three machine-building enterprises activity results on criterion of functional and resource integrity.

\begin{tabular}{|c|c|c|c|}
\hline Effect & $\begin{array}{l}\text { Result of } \\
\text { Impact }\end{array}$ & Source & $\begin{array}{l}\text { Characteristics } \\
\text { of selection }\end{array}$ \\
\hline $\begin{array}{l}\text { Increased } \\
\text { performance }\end{array}$ & Positive & $\begin{array}{l}\text { B. Crepon, } \\
\text { E. Duguet, } \\
\text { J. Mairesse, } \\
1998\end{array}$ & $\begin{array}{l}4,164 \\
\text { companies in } \\
\text { France in } 1990\end{array}$ \\
\hline $\begin{array}{l}\text { Increased } \\
\text { market } \\
\text { share }\end{array}$ & Positive & $\begin{array}{l}\text { S. Olav Nes, } \\
\text { A. Leolahti, } \\
1997\end{array}$ & $\begin{array}{l}1,848 \\
\text { Norwegian } \\
\text { firms, period } \\
\text { from } 1990 \text { to } \\
1994\end{array}$ \\
\hline $\begin{array}{l}\text { Increased } \\
\text { profitability }\end{array}$ & $\begin{array}{l}\text { Unclear } \\
\text { (not } \\
\text { available) }\end{array}$ & $\begin{array}{l}\text { T. Sandven, } \\
2001\end{array}$ & $\begin{array}{l}873 \text { Norwegian } \\
\text { production } \\
\text { firms in } 1992 \\
\text { and } 640 \text { firms } \\
\text { in the period } \\
\text { from } 1995 \text { to } \\
1999\end{array}$ \\
\hline $\begin{array}{l}\text { Temporary } \\
\text { monopoly } \\
\text { powers }\end{array}$ & Positive & $\begin{array}{l}\text { J. Peters, } \\
1997\end{array}$ & $\begin{array}{l}\text { 410 German } \\
\text { industrial firms } \\
\text { in } 1996\end{array}$ \\
\hline $\begin{array}{l}\text { Increased } \\
\text { return on } \\
\text { investment }\end{array}$ & $\begin{array}{l}\text { Unclear } \\
\text { (not } \\
\text { available) }\end{array}$ & $\begin{array}{l}\text { Baldwin, } \\
\text { Hanel, et al., } \\
2000\end{array}$ & $\begin{array}{l}\text { 5,729 Canadian } \\
\text { companies in } \\
1993\end{array}$ \\
\hline $\begin{array}{l}\text { Increased } \\
\text { firm value }\end{array}$ & Positive & $\begin{array}{l}\text { Loof, } \\
\text { Heshmati, et } \\
\text { al., } 2001\end{array}$ & $\begin{array}{l}1,062 \text { Finnish } \\
\text { companies, } \\
1,315 \\
\text { Norwegian and } \\
746 \text { Swedish } \\
\text { companies in } \\
\text { the period from } \\
1988 \text { to } 1999\end{array}$ \\
\hline $\begin{array}{l}\text { Competitive } \\
\text { advantages }\end{array}$ & Positive & $\begin{array}{l}\text { Gurkov, } \\
2003\end{array}$ & $\begin{array}{l}\text { Survey among } \\
\text { directors of }\end{array}$ \\
\hline
\end{tabular}

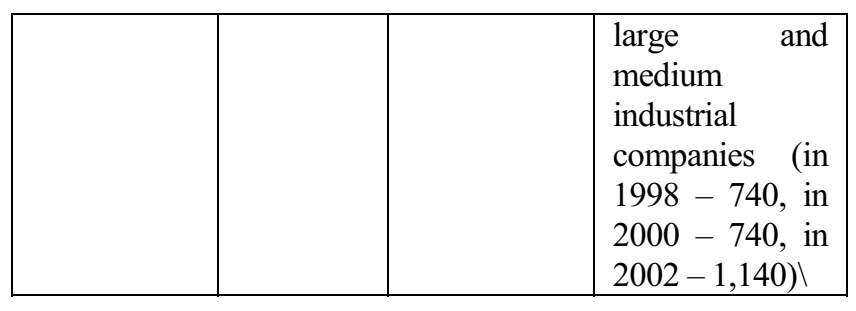

However, it is difficult to identify the exact impact of implemented innovative processes on all the above indicators because in this assessment, the innovative activities of the company should be reviewed as the only events and activities performed by the company, i.e., the current functioning of the company and multiple factors which have impact on it should be disregarded.

\section{Conclusion}

Thus, integration of results achieved directly through implementation of the innovative process and functioning of OEM enables identification of the key effects. In the aspect of organizational and management effectiveness - effect of reduced time for innovative process implementation. In terms of social effectiveness - effect of competitive advantages of produced product. Production effectiveness shall be interpreted as the effect of increased workforce productivity, reduced losses due to defects, reduced expenses on warranty services.

The, the final economic effect of implementation of a specific innovative process and OEM functioning shall be calculated using the following equation, eqn.(22):

$$
\begin{aligned}
& E_{I P}=E_{\text {compet. }}+E_{\text {loss_to_defect }}+E_{\text {reduc.time }}+E_{\text {warranty }}, \\
& +E_{\text {performance }}
\end{aligned}
$$

where Ecompet. - increase of revenues from sale of company products due to increased demand as compared with sales before implementation of innovative process or analogs existing in the market (including new contracts);

Eloss to defect - economic effect of reduced losses caused by defects (including returns by buyers);

Ereduc.time - savings achieved due to reduced time for implementation of innovative process (measured based on notional value of 1 standard hour);

Ewarranty - savings achieved due to reduced expenses on warranty services (based on reduction in the number of claims);

Eperformance - effect of increased volume of goods over the reviewed period.

Due to timely calculations of indicators of final efficiency, reserves can be identified and strategy of their use can be developed based on concretization of objectives and, finally, a highly efficient mechanism for implementation of scientific and technical achievements can be created in the framework of an industrial company.

Thus, practical application of this method will contribute to production of products which conform to the consumer expectations while minimizing one-time 
and continued costs for implementation of innovative processes and ensure company profit growth due to increased share and segments of consumers.

\section{References}

1. S.N. Yashin, E.V. Koshelev, S.A. Makarov, Analysis of the effectiveness of innovative activity (St. Petersburg, BHV, 2012)

2. P. Druker, Innovation and Entrepreneurship (Williams, Kiev, 2007)

3. M.N. Mescon, M. Albert, F. Khedouri, Management (Delo, Moscow, 1992)

4. A.E. Gerasimov, Innovations, 12(9) (2001)
5. K.K. Prakhalad, M.S. Krishnan, The space business innovation. Creating value together with the consumer (Alpina publisher, Moscow, 2012)

6. Federal State Autonomous Educational Institution of Higher Professional Education "Ural Federal University named after the first President of Russia B.N.Yeltsin" (UrFU). Graduate School of Economics and Management. http://urfu.ru/ru/.

7. ISO 9000-2008. Quality management systems. Fundamentals and vocabulary (Standards Publishing House, Moscow, 2009).

8. Ural Branch of the Russian Academy of Sciences. The Institute of Economics. http://www.uiec.ru/.

9. A.A. Chulok, Innovations, 12(5) (2004) 